\title{
3D printing and morphological characterisation of polymeric composite Scaffolds
}

\author{
Bankole I. Oladapo ${ }^{\mathrm{a}, \mathrm{b}, *}$, Sikiru O. Ismail ${ }^{\mathrm{c}}$, Mohsen Zahedi ${ }^{\mathrm{d}}$, Affan Khan ${ }^{\mathrm{a}}$, Hazrat Usman ${ }^{\mathrm{a}}$ \\ ${ }^{a}$ School of Engineering and Sustainable Development, De Montfort University, Leicester, United Kingdom \\ ${ }^{b}$ Engineering Department, Coventry University, Scarborough, United Kingdom \\ ${ }^{c}$ Centre for Engineering Research, School of Engineering and Computer Science, University of Hertfordshire, \\ United Kingdom \\ ${ }^{d}$ Department of Computer Engineering, University of Isfahan, Iran.
}

\begin{abstract}
3D-printing is an efficient method of designing customised structures and producing synthetic bone grafts appropriate for bone implants. This research aimed to manufacture a new multi-functionalised 3D-printed poly(lactic acid)/carbonated hydroxyapatite (PLA/cHA) scaffolds with mass proportions of 100/0, 95/5 and 90/10 in a bid to verify their potential application in tissue regeneration. The filaments of these hybrid materials were obtained by extrusion technique and subsequently used to manufacture the 3D-printed scaffolds, using a fused deposition modelling (FDM) technique. The scaffolds were characterised based on their thermal properties, microstructure and geometry by differential scanning calorimetry (DSC), scanning electron microscopy (SEM) and energy dispersive x-ray spectroscopy (EDS), respectively, in addition to determination of their apparent porosities. The degradation of the scaffolds and the liberation of degradation products were evaluated in in vitro for different days under simulated physiological conditions. New microanalyses of mechanical behaviour of the materials: tensile and compression stresses, density, frequency analysis and optimisation with DSC were performed. While, evaluation of the surface luminance structure and the profile structure of the nanostructured PLA composite materials was done by SEM, in 3D printed form. The filter profile of cross-sectional view of the specimen was extracted and evaluated with Firestone curve of the Gaussian filter; checking the roughness and waviness profile of the structure. It was observed that the thermal properties of the composites were not affected by the manufacturing process. The microstructural analysis showed the effective incorporation of the ceramic filler in the polymer matrix as well as an acceptable PLA/cHA interaction. The degradation tests showed the presence of calcium and phosphorus in the studied medium, confirming their liberation from the composites during the incubation periods.
\end{abstract}

Keyword: PLA/cHA, biomaterial, composites, bone regeneration, hybrid nanocomposite.

\section{Introduction}

Recent advances in medicine have enabled growth in the life expectancy of the world population. The published data in May 2014 by the World Health Organisation showed a six-year increase in average global life expectancy between 1990 and 2012 [1-2]. Over the years, the performance of our organs, tissues and the entire organism is naturally compromised. This compromise makes it necessary to use medical interventions in the reconstruction and repair of tissues damaged by injuries, resulting from factors such as reduction in mechanical resistance. Thus, maintaining the health of individuals becomes indispensable, resulting to a greater stimulus for several studies in this area [3-4]. The bone grafts used in the transplants can be autogenous, allogenous or xenogenic. Autogeneous occurs when the donor is the recipient (himself). Allogenous is when the donor is of 
the same species. Xenogenic is when the donor is of another species. However, transplants have significant disadvantages, such as rejection of the graft by the recipient organism in the case of non-autogenous grafts and infections $[5,6]$. Tissue engineering uses strategies for the reconstruction and repair of these compromised tissues, among which the use of biomaterials is highlighted as an alternative to conventional bone transplants of autogenous, allogenic and xenogenic [7, 8].

Biocompatible polymers are materials intended for the manufacture of bone regeneration frameworks, among which polylactic acid (PLA) is distinguished by its safety history when used in the human clinic. However, such materials are known to have low mechanical strengths when compared with other non-polymeric materials $[9,10]$. Calcium phosphates, such as hydroxyapatite (HA), are intended to play important roles, because they are biocompatible and bioactive, and assisting the regeneration of damaged tissue [11,12]. Due to its low resorption rate, studies have been carried out to modify hydroxyapatite and improve its resorption. These studies included the replacement of phosphate groups $\left(\mathrm{PO}_{4}^{-3}\right)$ by carbonate groups $\left(\mathrm{CO}_{3}{ }^{-2}\right)$, which modified the crystal structure of $\mathrm{HA}$, increasing its solubility, favoring osteoclast resorption. Hydroxyapatite modified by substitution of $\mathrm{PO}_{4}^{-3}$ by $\mathrm{CO}_{3}^{-2}$ is called carbonated hydroxyapatite [12-14].

The production of 3D biopolymer matrix scaffolds from hybrid materials has been the focus of promising studies in tissue engineering. Thermoplastic biopolymer matrix frameworks have been successfully developed by the fusion and deposition modelling (FDM) through 3D printing technique. The success of manufacturing such frameworks is attributed to the fact that the technology is a fast, economical and better-performing alternative in the production of highly complex custom parts, when compared with conventional or subtractive manufacturing methods $[15,16]$.

The mixture of polymers and ceramics offered many opportunities and, at the same time, provided biological benefits to improve the mechanical properties of ceramics. For instance, PLA is a compound that depends on aliphatic and biodegradable polyester base. It has been shown that it increased in a dose-dependent manner. Similarly, this was demonstrated in the diametral tensile strength of the PLA diameter, as reported by various studies on carbonated hydroxyapatite (cHA) [16-18]. The sizes of ceramic particles can be used to adjust the mechanical properties of the compounds: HA nanoparticles. There was an increase in the compressive strength of the compounds, when compared with HA microparticles. From the comparability with semi-transparent bones, when micro-embedded in the size of $6 \mu \mathrm{m}$, it showed osteoconductivity of PLA and cHA as well as rabbit notch. Similarly, the porous PLA/cHA composite demonstrated successful treatment of significant cranial defects [19-21].

Tissue engineering consisted of development and manipulation of cells and tissues to replace, repair or support damaged tissues has been studied. It was able to restore or improve compromised tissue biological functions, as a result of trauma in general through biochemical, genetic and scientific studies in the field of materials engineering [22,23]. One of the strategies of tissue engineering is the use of biomaterials to develop functional supports for damaged tissues or organs; to regenerate or replace them. Materials can be seeded with the patient's human body cells before implantation to facilitate growth and regeneration of damaged tissue [2426]. In addition to the chemical properties, it has been suggested that it affected the level of structural properties of biological materials and osteoinductivity [27,28]. This phenomenon is caused by microporosity. Also, the 
specific surface area of the ceramic shows that the geometric properties at the macro level of the material have a significant effect on the bone formation, caused by the material. The heterotropic bone formation has been demonstrated explicitly in pores, and rarely occurs around the implant site. Protected environment of FDM is used for the regeneration of fish bones. PLA/cHA has been developed using extrusion techniques, as frames in the production of frames.

This research aimed to microanalyse and manufacture hybrid PLA scaffold composites, containing cHA, in different mass ratios. The scaffolds are to be applied in bone tissue regeneration through the use of $3 \mathrm{D}$ printing. In addition, further rationales behind this study are to improve biocompatibility and properties: bioactivity of osteointegration of these materials and remove deficiency in PLA composites. The development of inorganic fillers in biopolymer matrices for the production of the frameworks or scaffolds was done with 3D printing. Nanostructural analysis of the samples on different days and mass ratios of the PLA/cHA was conducted. A filament with constant diameters of approximately $1.75 \mu \mathrm{m}$ PLA containing different proportions of cHA, fabricated by extrusion method was extensively analysed. The porosity and biocompatibility analyses of the PLA/cHA frameworks by FDM technique, in vitro degradation evaluation of the samples and cytotoxicity assessment were done with software.

\section{Materials and methods}

Ingeo 2003D PLA with 4\% isomer content was used as a matrix of the composites, while cHA particles were used as composite loading reinforcements. They were purchased from the Brazilian centre for physical research $(\mathrm{CBPF})$, synthesised at $37{ }^{\circ} \mathrm{C}$, with a particle diameter of less than $90 \mu \mathrm{m}$. The cHA loading was incorporated into the PLA matrix at mass ratios of PLA/cHA 100/0, 95/5 and 90/10, where the 100/0 ratio corresponds to the pure PLA. A physical mixing in a two-chamber roller mixing chamber was carried out at 160 ${ }^{\circ} \mathrm{C}$ with a speed of $40 \mathrm{rpm}$ for 10 minutes. After this process, the dough obtained was ground in a Willey SEIBT knife mill to get feed granules in the extruder. The PLA/cHA filaments were produced, coupled to a spool-type cooling tank and winder. The cHA percentage on different days at $90{ }^{\circ} \mathrm{C}$ for the feed, compression and metering zones, consecutively (Fig. 1). The thread rotation varied from 20 to $50 \mathrm{rpm}$ during the processes and the puller speed ranged from 25 to $35 \mathrm{rpm}$. 


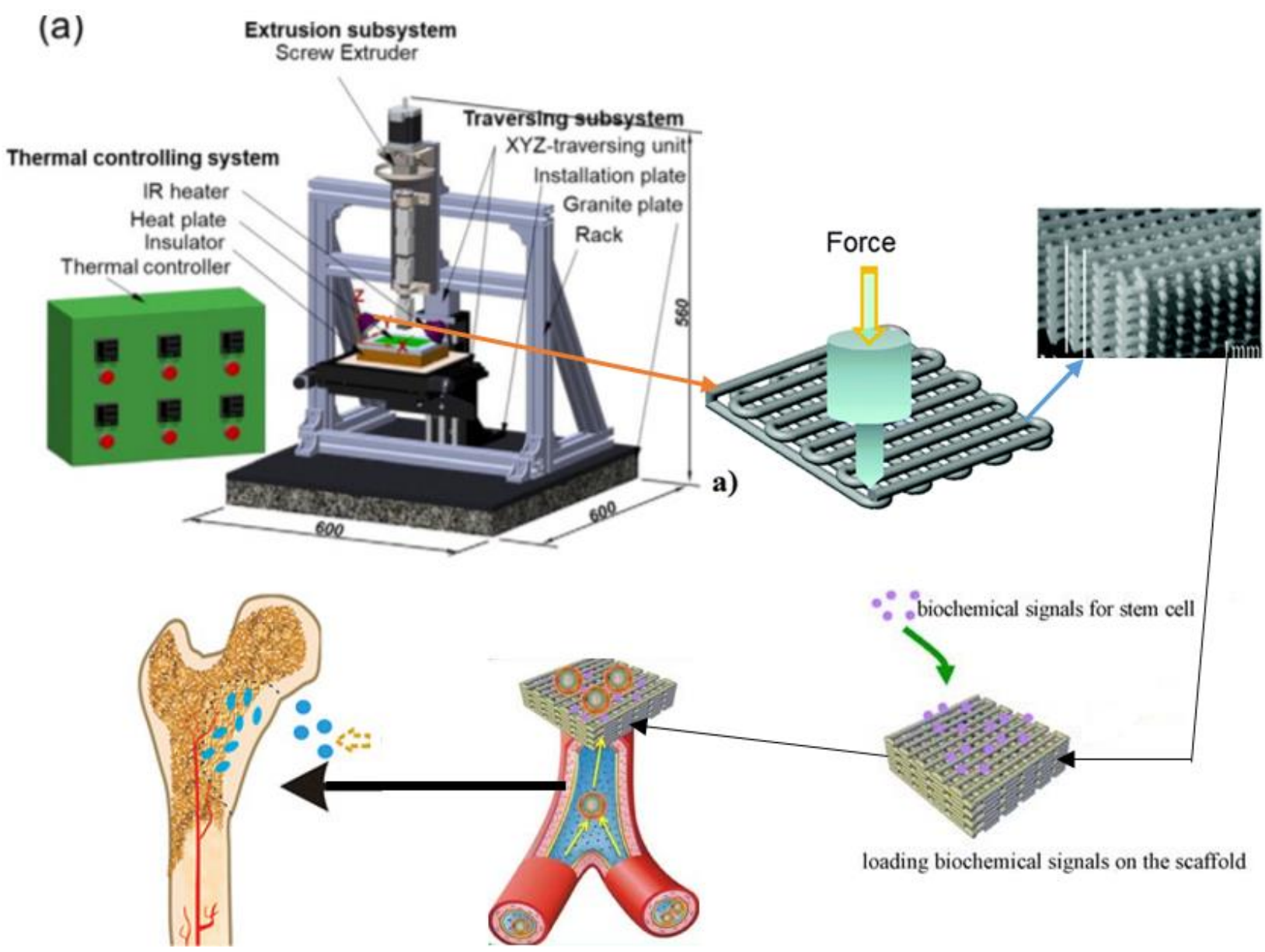

Fig. 1. The modelling process of PLA composite by FDM and biochemical loading signal on the scaffold for bone implant.

\subsection{Scanning electron microscopy and differential scanning calorimetry}

The materials used to obtain the composite of PLA matrix and cHA loading were characterised as commercially received after extrusion and printing of PLA/cHA. These were done with two heating cycles from $40{ }^{\circ} \mathrm{C}$ to $250{ }^{\circ} \mathrm{C}$, at a rate of $10{ }^{\circ} \mathrm{C} / \mathrm{min}$, to evaluate the thermal phenomena of the materials. The changes in their thermal behaviour within the processes and proportions evaluation and calculate of the degree of crystallinity of the materials were done using the Mountain $8^{@}$ Premium software. The watershed method detection for several particles was employed, which gave 82, having a projected area of $195.3 \mu \mathrm{m}^{2}$. The equivalent diameter of $11.90 \mu \mathrm{m}$ with a local height of $10.52 \mathrm{~nm}$ was set to a roundness and compactness values of 0.4182 and 0.6333 , respectively, with a pitch of $19.10 \mu \mathrm{m}$, as shown in Figs. 2(a)-(b). 
PLA, 100/0

(a)

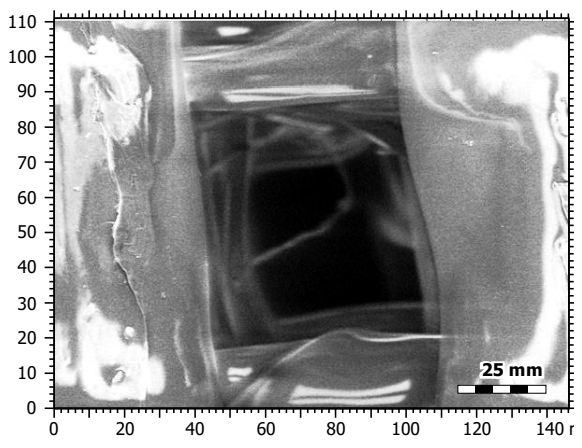

(b)

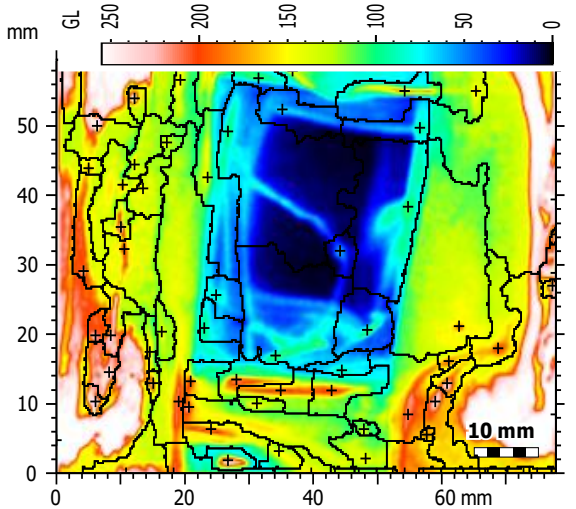

cHA, $5 \%$
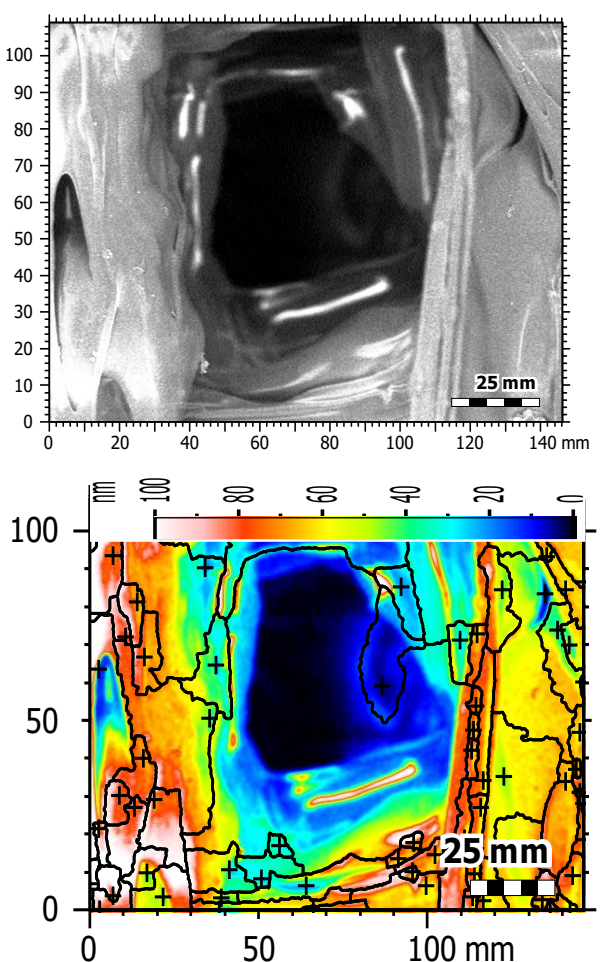

cHA, $10 \%$
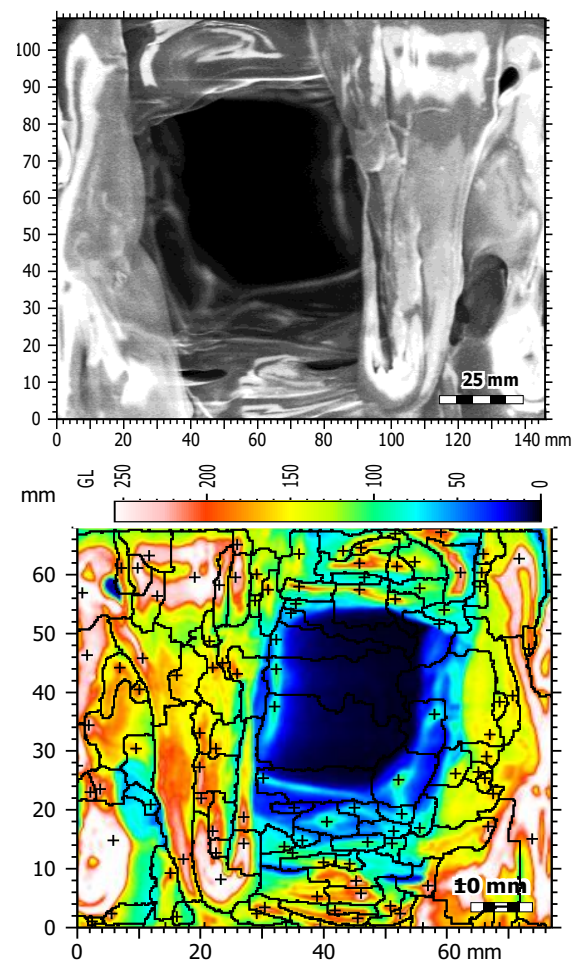

Fig. 2. A representative of cHA 0\%, 5\% and 10\% composite, showing (a) the high-pass robust Gaussian filter of 285 point and (b) particle microanalysis of motif specification.

The degree of crystallinity was evaluated with Eq. (1), where $X_{c}$ is the degree of crystallinity, $\Delta H_{f}$ is the fusion enthalpy obtained on other heating, and $\Delta H_{f 100}$ is the fusion enthalpy for $100 \%$ crystalline PLA and $W_{f}$ represents the mass fraction of PLA in the composite. The value for $100 \%$ crystalline PLA was considered equal to $93.1 \mathrm{~J} / \mathrm{g}$.

$$
X c=\frac{\left(\Delta H_{f}\right)}{W_{f} \times \Delta H_{f 100}} \times 100
$$

The morphology of the PLA/cHA scaffolds was analysed by SEM, operated at $15 \mathrm{kV}$ to $20 \mathrm{kV}$ beam acceleration voltage in different increments. Aspects such as porosity, pore size, pore connectivity and crosssections were evaluated. The cross-sections of the samples were evaluated by fracturing them in nitrogen. All micrographs were performed without metallic coating. Chemical elements present in the PLA/cHA scaffolds were identified by analysing the sample area and mapping by SEM/EDS in a digital surface software (Mountain $8^{@}$ Premium). The scaffolds were analysed on their surfaces and cross-sections before and after 672 hours of release at $\mathrm{pH}$ values of 7.4 and 4.0 , to observe a possible variation in the intensity of calcium (Ca) and phosphorous $(\mathrm{P})$ peaks, due to the release of these ions during the in vitro degradation test. 


\subsection{Morphological characterisation}

The filaments obtained in the extrusion process as well as the scaffolds obtained in 3D printing were characterised by their visual appearance, dimensional size, volume and diameter characteristics, according to microanalysis. The filaments have their regularity examined by using a digital caliper to measure their diameters throughout their lengths. An evaluation by optical microscopy allowed analysis of morphology of the printed samples, within the micrometre and nanometre range. The filament deposition and arrangement of the printed layers were observed, using digital surface software in stereoscopic microscope. The printed sketches also have their masses weighed on an analytical scale of four decimal places. The method of watershed detection of 159 number of particles was generated, as depicted in Fig. 2. The projected area of $102.5 \mu \mathrm{m}^{2}$ with local height of $12.21 \mathrm{~nm}$, with an interior edgex of ' $\mathrm{X}$ ' and ' $\mathrm{Y}$ ' parameters to be $146.5 \mu \mathrm{m}$ and $0.0 \mu \mathrm{m}$. The wavelength was $146.5 \mu \mathrm{m}$ at an angle $0^{\circ}$ with different frequency magnitudes at phase angle of $-2.57^{\circ}$ (Fig. 3).
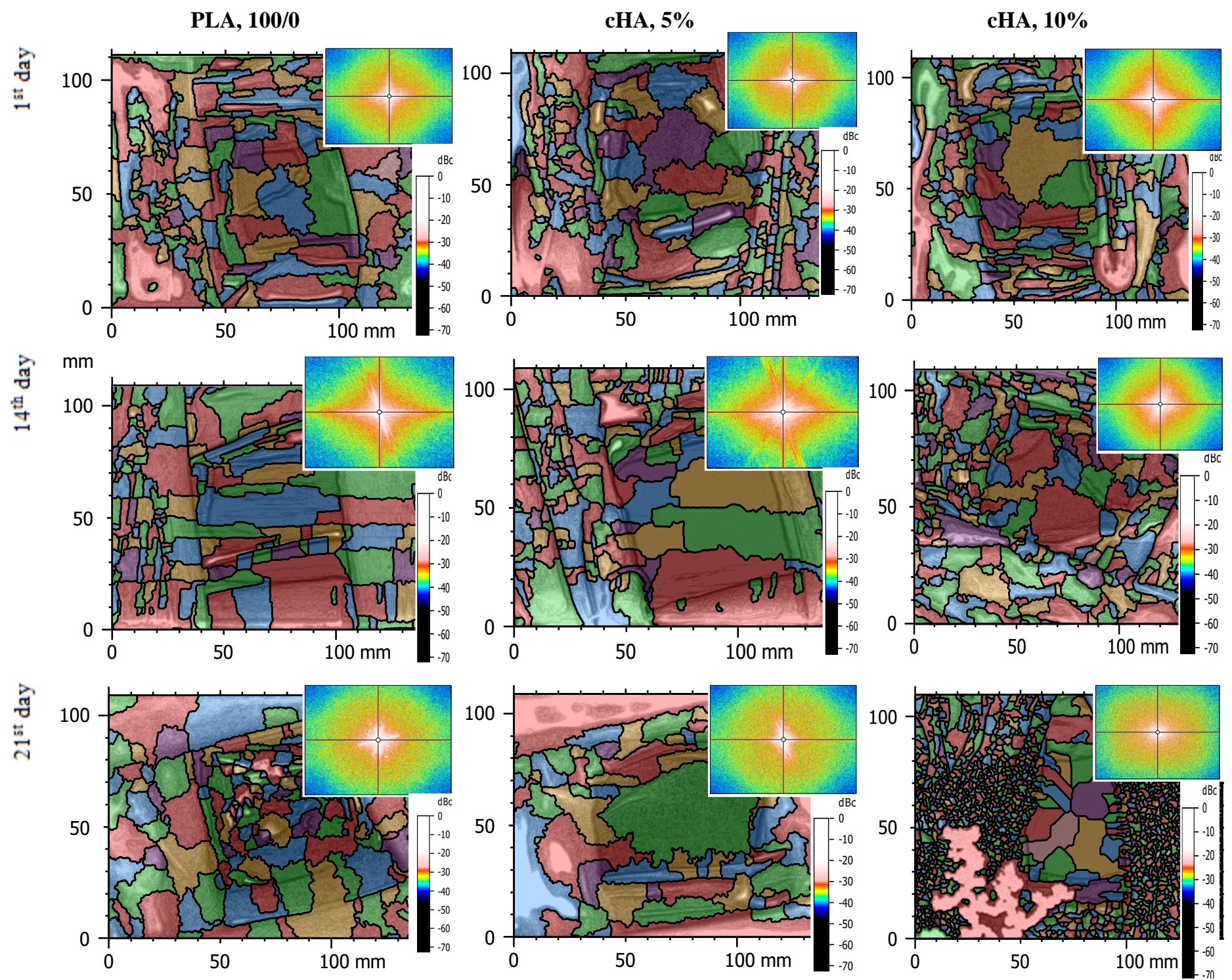

Fig. 3. Particle microanalyses of Karhunen-Loeve (KL) transform and frequency spectrum of the images. 


\subsection{Determination of apparent porosity}

The apparent porosity of the scaffolds obtained was determined in accordance with ASTM F2450 (2010), following the Archimedes' principle, assuming that everybody soaked in a fluid undergoes a vertical upward force with an intensity equals to the weight of the fluid displaced by the body. A hydrostatic balance was used to measure the mass of the five samples of PLA/cHA scaffolds for each of the ethanol-immersed 100/0, 95/5 and 90/10 proportions, using a digital surface software (Mountain $8{ }^{\circledR}$ Premium). Sample masses before and after immersion were used, together with ethanol density, to determine the apparent density of the scaffolds, as described in Eq. (2).

Apparent density $=\frac{M_{d r y^{*}} \rho_{\text {ethanol }}}{M_{\text {wet }}-M_{d r y}}$

Sample sizes were measured with a caliper instrument to determine the actual volume of the scaffolds cube and an average of the actual volume was taken. The pore volume, $\mathrm{V}_{\text {pores }}$ could then be measured according to the relationship described in Eq. (3), for each of the five samples.

$\mathrm{V}_{\text {pores }}=\mathrm{V}_{\text {real }}-\frac{M_{d r y}}{\text { Apparent density }}$

The apparent porosity of the samples was finally determined according to Eq. (4).

Apparent porosity $=\frac{V_{\text {pores }}}{V_{\text {real }}} \mathrm{X} 100$

Both roughness and decomposition microanalyses of the scaffolds were evaluated by simulating testing, according to ISO 10993 parts 12. This test evaluated the cell viability by calorimetric measurement of cell metabolic activity in the spectrophotometer. The yellowish, water-soluble tetrazolium salt was metabolically reduced by cell-oxidising enzymes into purple-blue formazan crystals, when metabolically active cells were present. Thus, the quantification of viable cells was done by the colour intensity detected by absorption. For this assay, mouse fibroblast cells, strain L-929, were used in a 96-well plate. Five scaffolds of each PLA/cHA ratio 100/0, 95/5 and 90/10 were immersed in $2 \mathrm{~mL}$ of BMEM culture medium for 24 hours. Pure extracts obtained after this period (100\%) and dilutions of these extracts at concentrations of 5\% and $20 \%$ were used as cell growth media. The cells treated with controls and samples were incubated for 24 hours at $37{ }^{\circ} \mathrm{C}$. The quantification of the cell viability was evaluated on a microplate reading spectrophotometer by detection in the UV, Synergy H4 model. A viable cell percentage ratio was obtained for a better understanding of the results.

\section{Results and discussion}

All PLA/cHA filaments produced at aggregates of 100/0, 95/5 and 90/10 were reasonably regular, as their diameters ranged from 1.60 to $1.75 \mu \mathrm{m}$ and were within the acceptable width of printing. The son-carbonated hydroxyapatite PLA filaments of PLA/cHA 100/0 showed transparency and a smooth texture, while the cHA PLA filaments of PLA/cHA 95/5 and 90/10 exhibited an off-white appearance and texture. Rugosity effects of both samples were intensified by the increase in cHA content. According to [31,33,34], roughly textured scaffolds provided cell anchorage and facilitate cell deposition, adhering better to tissues, while very smooth 
scaffolds were susceptible to micro-movements, which could cause damage to healthy tissue. Fig 4 shows the apparent effect of insertion and cHA content on the colouration of the PLA scaffolds and also a slight increase in the dimensions of the PLA/cHA 95/5 and 90/10 scaffolds. Summarily, Fig. 4 presents data of the dimensional deviations provided by the various PLA/cHA frameworks concerning the digital model made.

\subsection{Surface roughness}

The parameteric values for the Abbott-firestone curve dimensional deviation of KL-transformed scaffolds obtained by 3D printing and fractal complexity of scale-sensitive microanalysis have difference in upper and lower bearing areas to be $96.93 \mathrm{~nm}$. The spatial parameters areal material percentage $\operatorname{Smr}(\mathrm{c} 1)$ and inverse areal material percentage $\operatorname{Smr}(\mathrm{c} 2)$ were $5 \%$ and $95 \%$, respectively. A length-scale row method was used for the surface in vitro microanalysis of nanoparticle number and points to be 200 , having a smooth-rough crossover (SRC) threshold value of 1.0. The domain maximum scale value and SRC were $146.2 \mu \mathrm{m}$ and $2.231 \mu \mathrm{m}$, respectively, with a register line slope of $-9.498 \times 10^{-11}$ of the $\mathrm{x}$-axis of Fig. 4(a) and a register line slope of $1.122 \times 10^{-11}$ at $\mathrm{Y}$-axis with $\mathrm{R}^{2}$ value of 0.8910 . The fractal complexity (Lsfc), fractal dimension (Dls), scale of maximum complexity (Smfc) value and length-scale anisotropy (epLsar) were $9.498 \times 10^{-8}, 1.0,0.2911 \mu \mathrm{m}$ and $1.8 \mu \mathrm{m}$ at $5^{\circ}$, respectively.

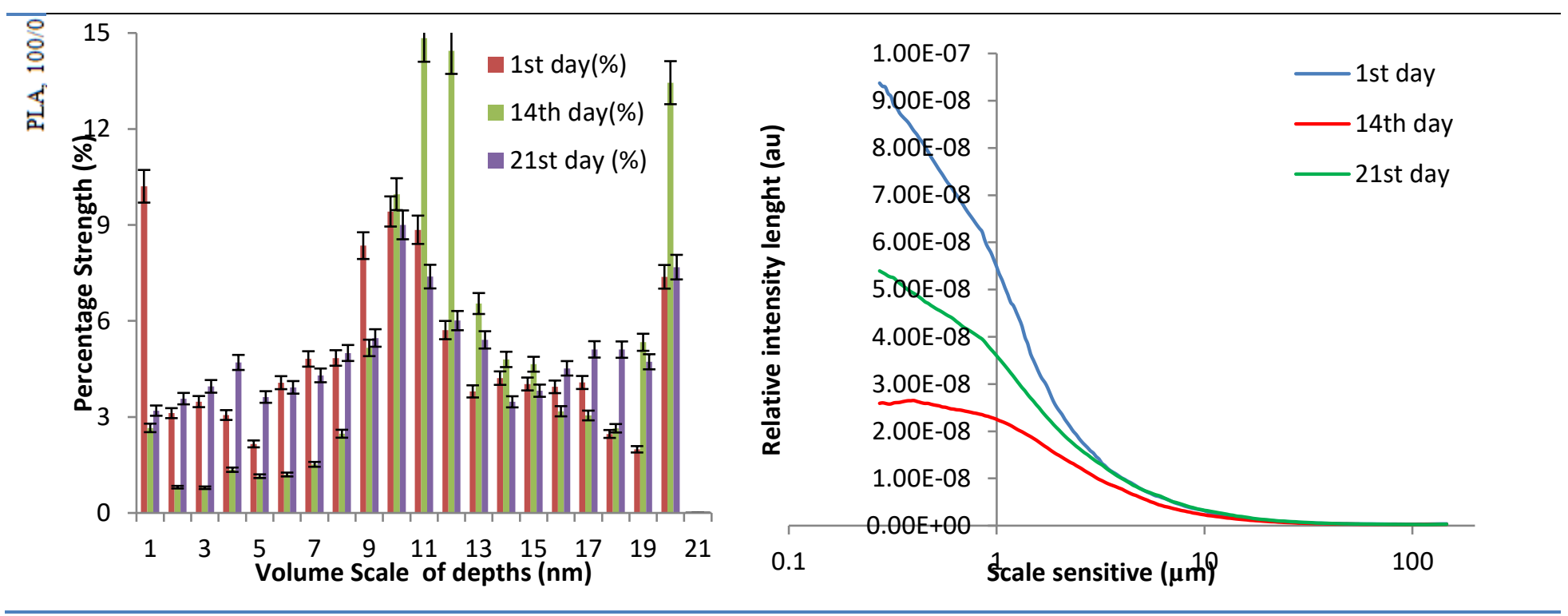



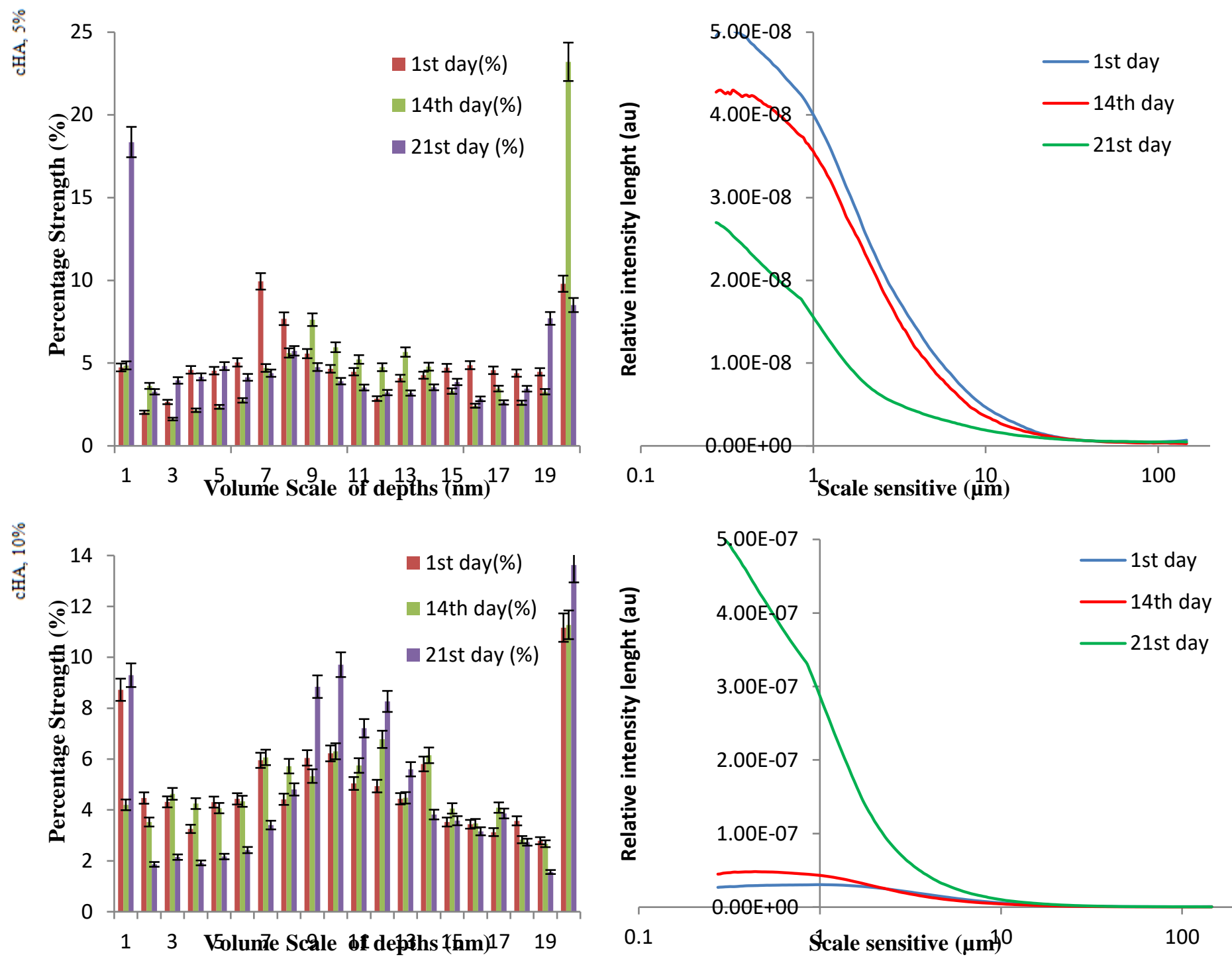

(a)

(b)

Fig. 4. A representation of the cHA samples,depicting (a) Abbott-Firestone curve dimensional deviation of bending strengths of the PLA/cHA composites with various modified cHA contents, ranging from $0 \%$ to $20 \%$ in KL-transformed scaffolds obtained by 3D printing and (b) fractal complexity of scale-sensitive microanalysis.

Bending strengths of the PLA/cHA composites with various modified cHA contents, ranging from $0 \%$ to $20 \%$ were estimated. To obtain the dimensions of the PLA/cHA scaffolds, three scaffolds of each PLA/cHA ratio were measured using a digital caliper. One of the reasons highlighted in the literature for the dimensional variation of printed parts was the dragline deposition and the print path [32-34]. This path was considered as a deposition strategy, referring to the way that the extruder nozzle travelled when tracing the geometry of each layer. By slicing the part, the software designed a way that tended to generate more significant material savings and faster construction of each section. However, the change in the nozzle trajectory sometimes resulted to a sudden pause in the line being constructed and the displacement of small portions of molten material, therefore changed the dimensions of the part on the $\mathrm{x}, \mathrm{y}$ and $\mathrm{z}$ axes [30-33]. The characteristics of the printed materials, such as viscosity, may also influence the dimensional deviation of the obtained parts. PLA/cHA 100/0 scaffolds were expected to vary dimensionally, due to the swell effects of the extrudate and the weight of the filaments 
themselves in the deposition process. Because during the deposition process, the material was still within its temperature range. It was softened and suffered from the weight of the other filaments, draining sideways.

\subsection{Mechanical properties}

DSC curve analysis was performed on the study of the thermal behaviour of the materials used as well as the composites obtained in the two processing steps. An increasing load content has effect on the scaffolds, it influenced the dimensional deviation. It was evident in the increased dimensions of the sides of the PLA/cHA 95/5 and 90/10 scaffolds and the reduction in height, with an exception of the PLA/cHA 90/10 sample. Therefore, dimentional deviation was directly proportional to the increase in carbonatite content of the scaffolds. The surface KL transformation of fractal dimensional microstructure and tolerance of root-mean-square gradient of hybrid parameters in ISO 25178 standard of the failure hypothesis is described in Fig. 5. This affects the percentage weight of cHA on the PLA filaments, generating scaffold size variation by flattening the deposited layers. This will be further explored.

\section{PLA, 100/0}
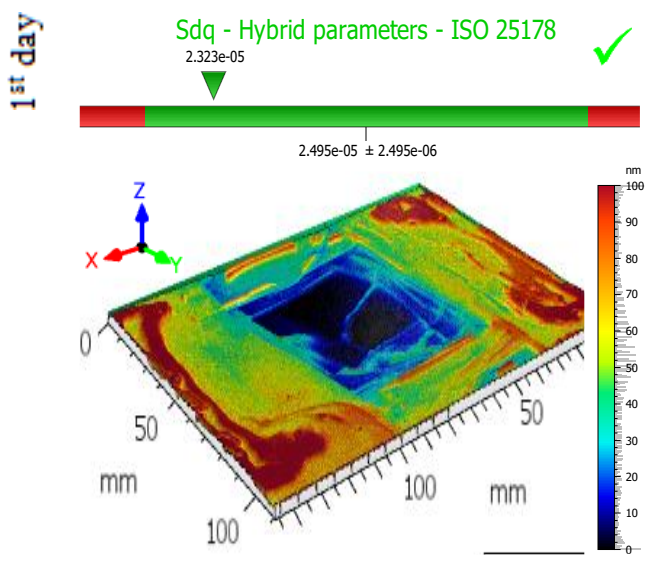

100

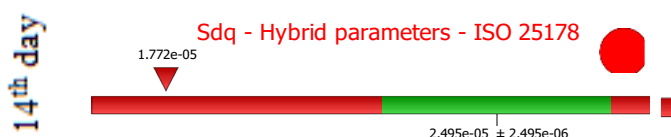

I

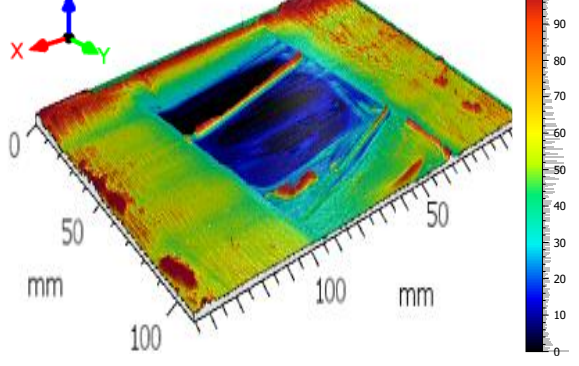

cHA, $5 \%$
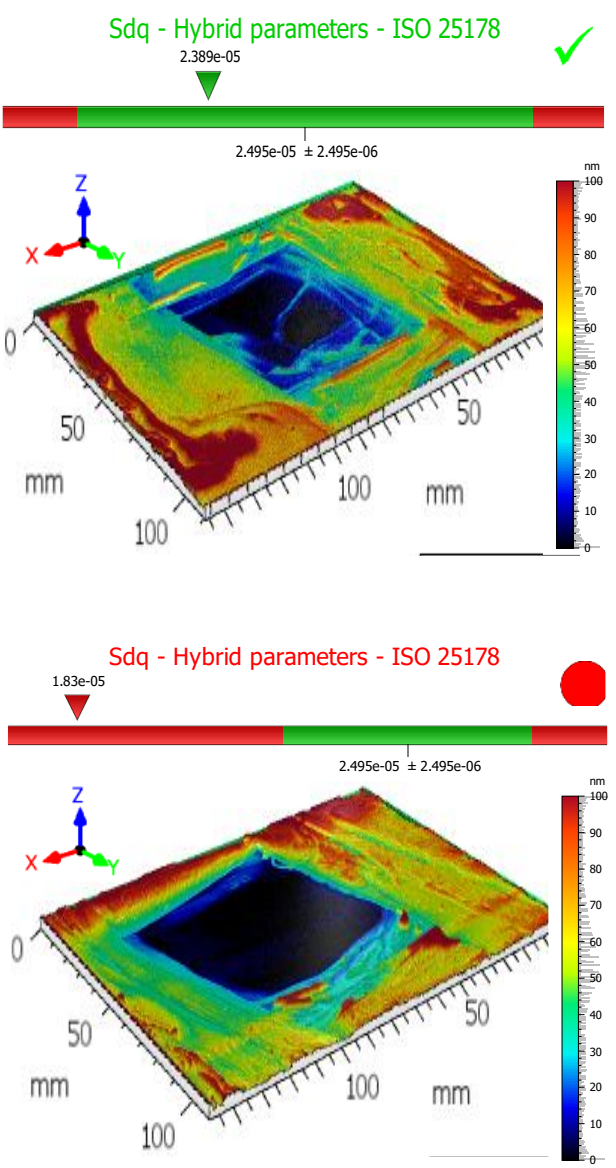

cHA, $10 \%$
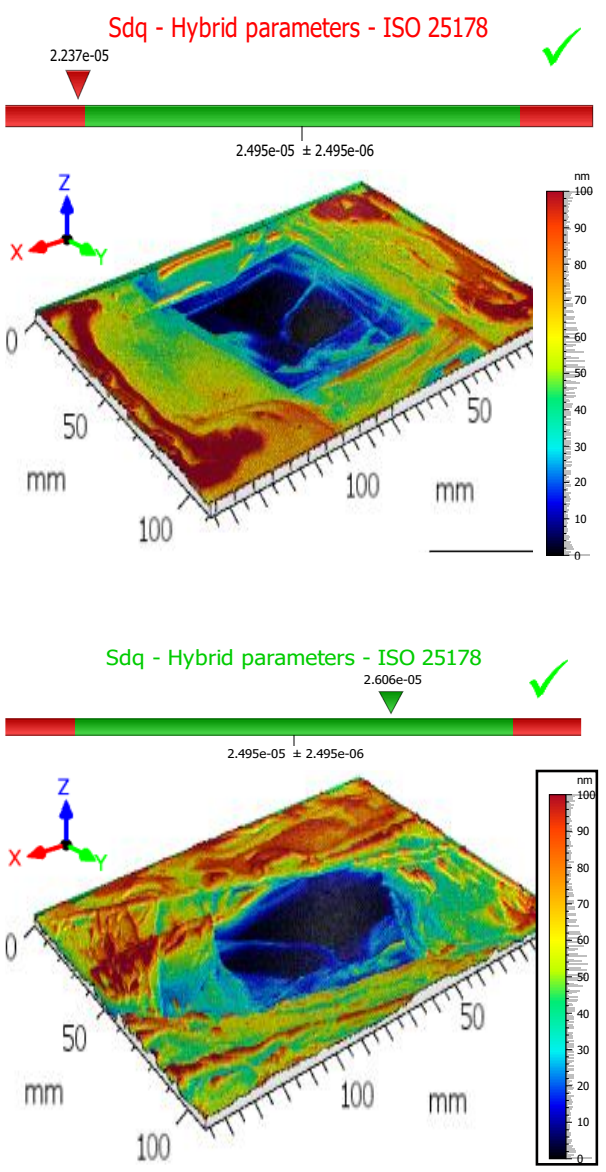

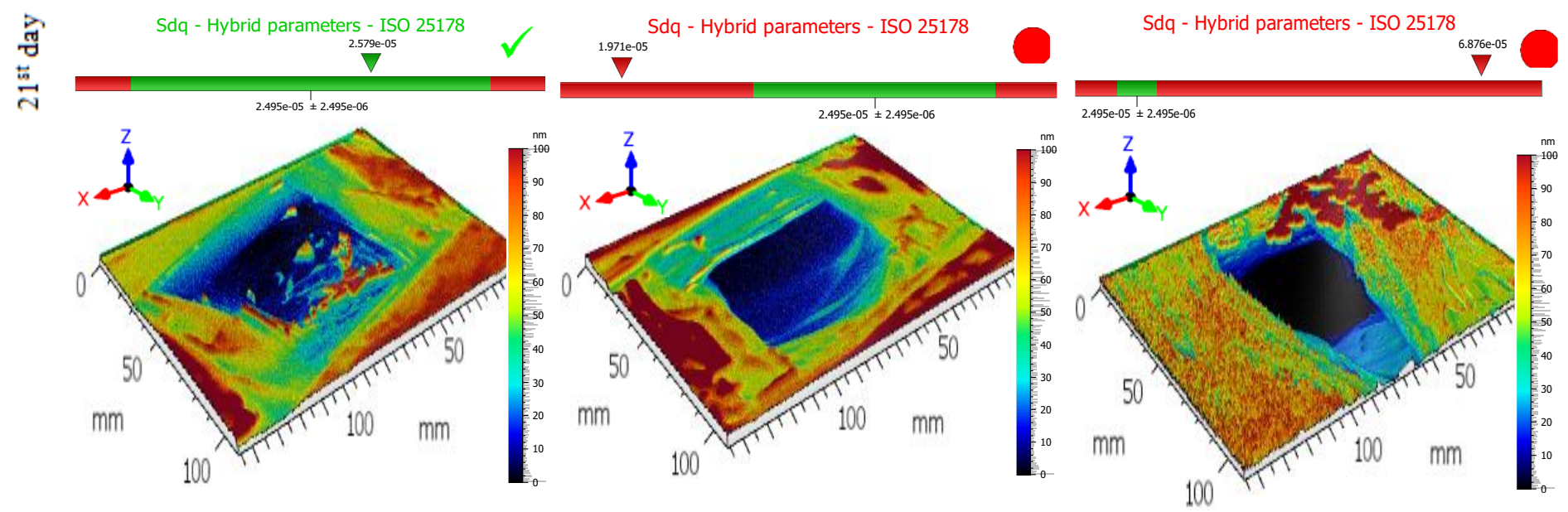

Fig. 5. Three-dimensional views of surface KL transformation of fractal dimensional microstructure and tolerance of root-mean-square gradient hybrid parameters in ISO 25178 standard of the failure hypothesis.

\subsection{Bioactive microstructural characterisation of scaffolds}

According to the values shown in Table 1 and the curves illustrated in the DSC (Fig. 6), the low crystallinity of PLA, which showed amorphous polymer behaviour was observed. From the $X_{c}$ values for PLA/cHA 100/0 filaments and scaffolds, it was observed that the processing used for the production of PLA/cHA scaffolds affected the degree of crystallinity of the polymer. The values further showed that a $10 \%$ cHA content considerably increased the degree of crystallinity of the material, which was evident not only by increasing $X_{c}$, but also by reducing the crystallisation temperature of the inserted materials by approximately $8{ }^{\circ} \mathrm{C}$ for $10 \%$ cHA. For a $5 \%$ percentage of cHA, no significant effect on polymer crystallinity was observed. This behaviour indicated that with $10 \% \mathrm{cHA}$ content, the charge dispersed more evenly through the polymeric matrix, with a larger contact area. Consequently, a better interaction with a more significant effect on PLA crystallinity was observed than that of $5 \%$ content.

PLA, 100/0

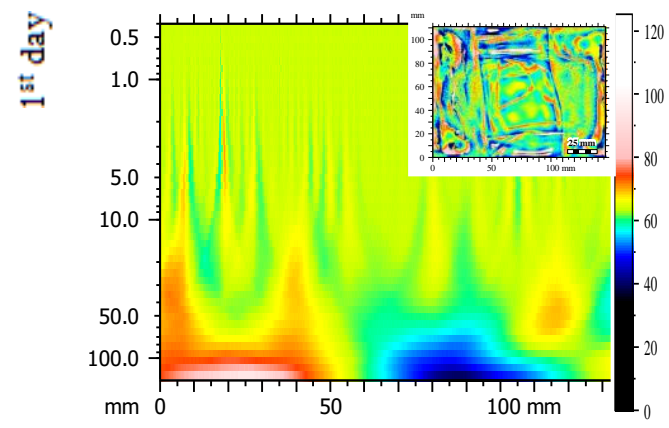

cHA, $5 \%$

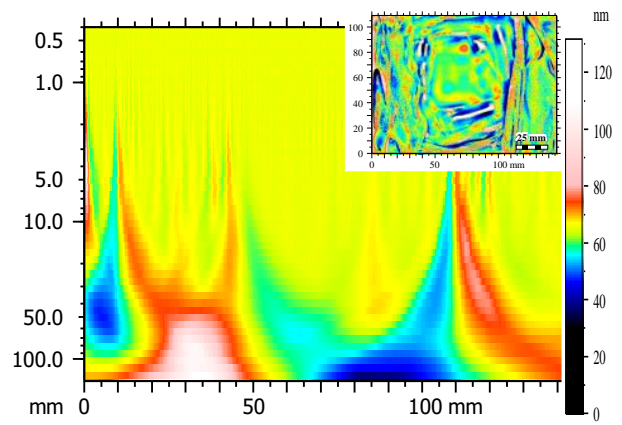

cHA, $10 \%$

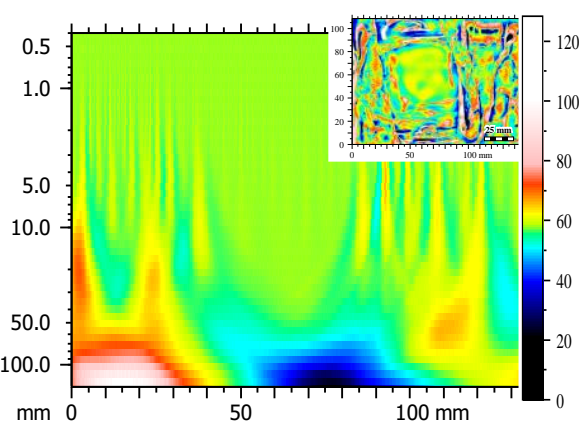



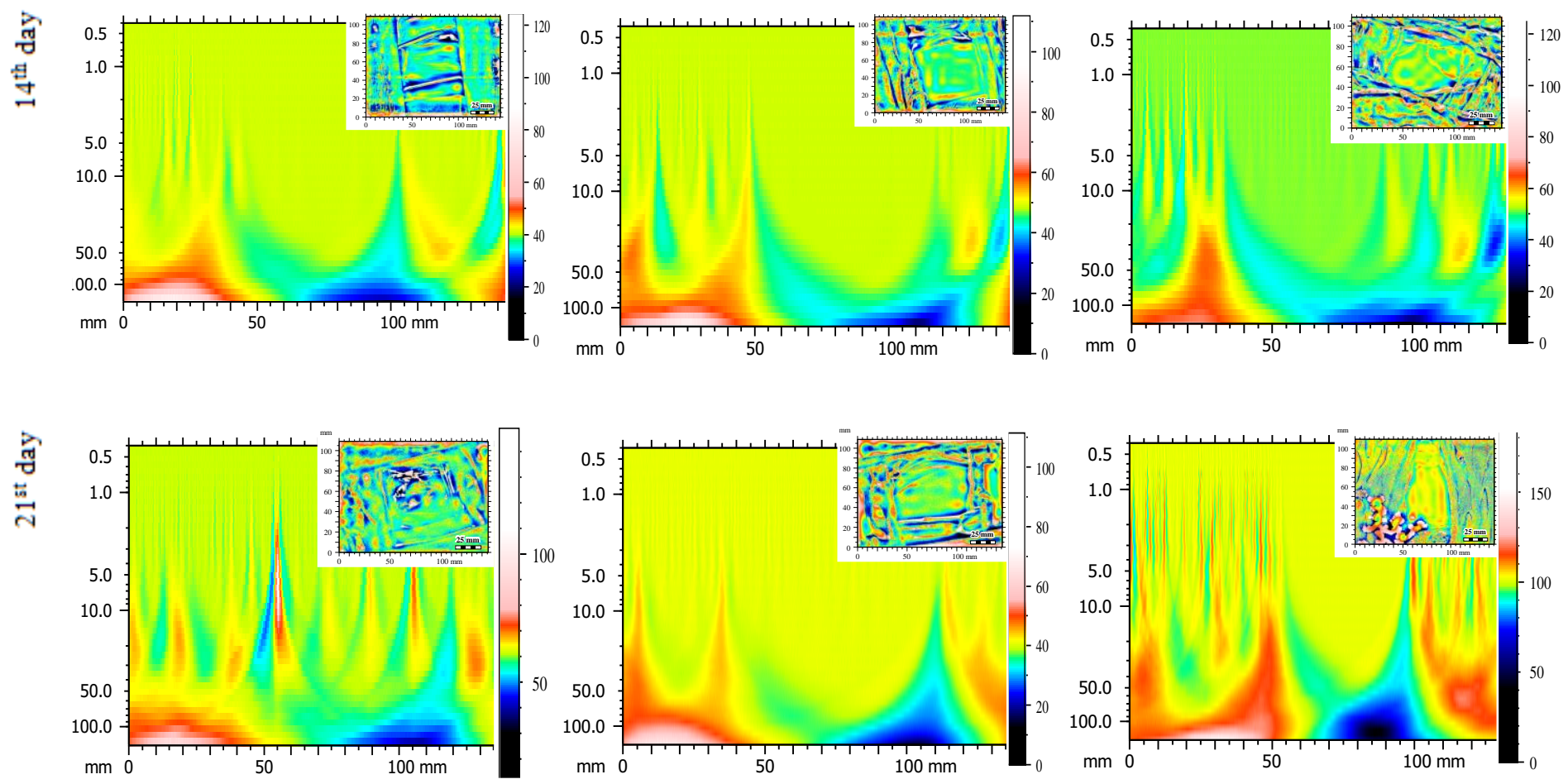

Fig. 6. Roughness wavelet filter of Daubechies of porosity and continue wavelet decomposition settings of

Daubechies.

All the materials exhibited semicrystalline material behaviour, with an exception of PLA pellets. PLA pellets showed an amorphous behaviour. With a change in the characteristic glass transition baseline $\left(T_{g}\right)$ - secondorder transition occurred in the amorphous phase of the material, exothermic peak crystallisation $\left(T_{c}\right)$ and crystalline fusion endothermic peak $\left(T_{f}\right)$ - referred to the melting of crystals of the crystalline phase of the material. The thermograms obtained from the thermogravimetric analysis of the materials are shown in Fig. 6. From Fig. 7, the average power spectrometer density of the wavelet for each sample was 32, represents in the DSC, having a zooming factor of $\mathrm{x} 4$ with several nano iterations particle, smoothing windows function of a reasonable wavelength of $18.33 \mu \mathrm{m}$. The amplitude of the sample was $5.621 \mathrm{~nm}$ in the spectrometer reading, having a dominant wavelength of $26.85 \mu \mathrm{m}$ and a maximum amplitude of $10.29 \mathrm{~nm}$.

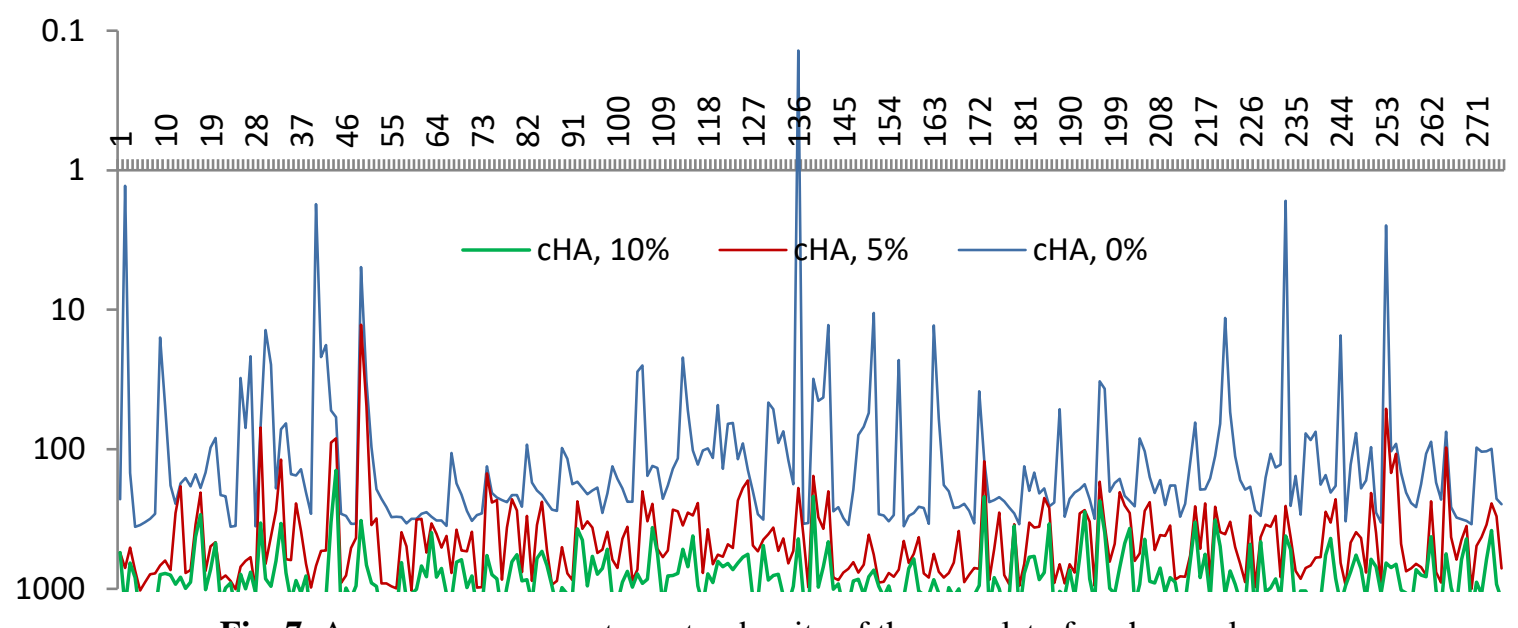

Fig. 7. Average power spectrometer density of the wavelet of each sample. 
The degradation processes of PLA and PLA/cHA composites also occurred in a single step. It can be observed that the methods of obtaining the scaffolds did not significantly change the material degradation temperature range, except for the PLA/cHA 100/0 scaffold. This may be interpreted that there was no significant change in the structure of the PLA during the production of the frameworks, despite the numerous thermomechanical treatments suffered by the material. Only the PLA/cHA 100/0 framework showed a reduction in the initial degradation temperature $\left(T_{i}\right)$ of $22.8^{\circ} \mathrm{C}$, when compared with the PLA pellet and $20.3{ }^{\circ} \mathrm{C}$ after the 3D printing process. Thus, it can be concluded that the frameworks containing cHA percentage ef PLA/cHA 95/5 and 90/10 were more thermally stable than the pure PLA framework. The initial degradation temperature of the PLA/cHA scaffolds increased by $22.8{ }^{\circ} \mathrm{C}$ for the $5 \%$ cHA framework and an increase of $22.9{ }^{\circ} \mathrm{C}$ for the $10 \%$ cHA framework. This result elucidated a positive effect of cHA insertion on the PLA thermal resistance to 3D printing scaffolding processing. There was no significant variation in the $T_{\max }$ and $T_{\text {final }}$ values of the scaffolds, as a function of the cHA content present. The microanalysis of the peak count distribution of the nanoparticle fractal analysis method was that of an enclosing box with a fractal dimension of 2.570, having the first slope of 2.57 with first $\mathrm{R}^{2}$ value of 0.9967 . The second slope of the fractal analysis KL transform and $\mathrm{R}^{2}$ were -2.57 and 0.9967, respectively (Fig. 8). The parameteric value of isotropy of the materials in the first direction was $20.50^{\circ}$, at second direction of $14.0^{\circ}$, and third direction of $89.98^{\circ}$ for the texture direction, as depicted in Fig. 8.
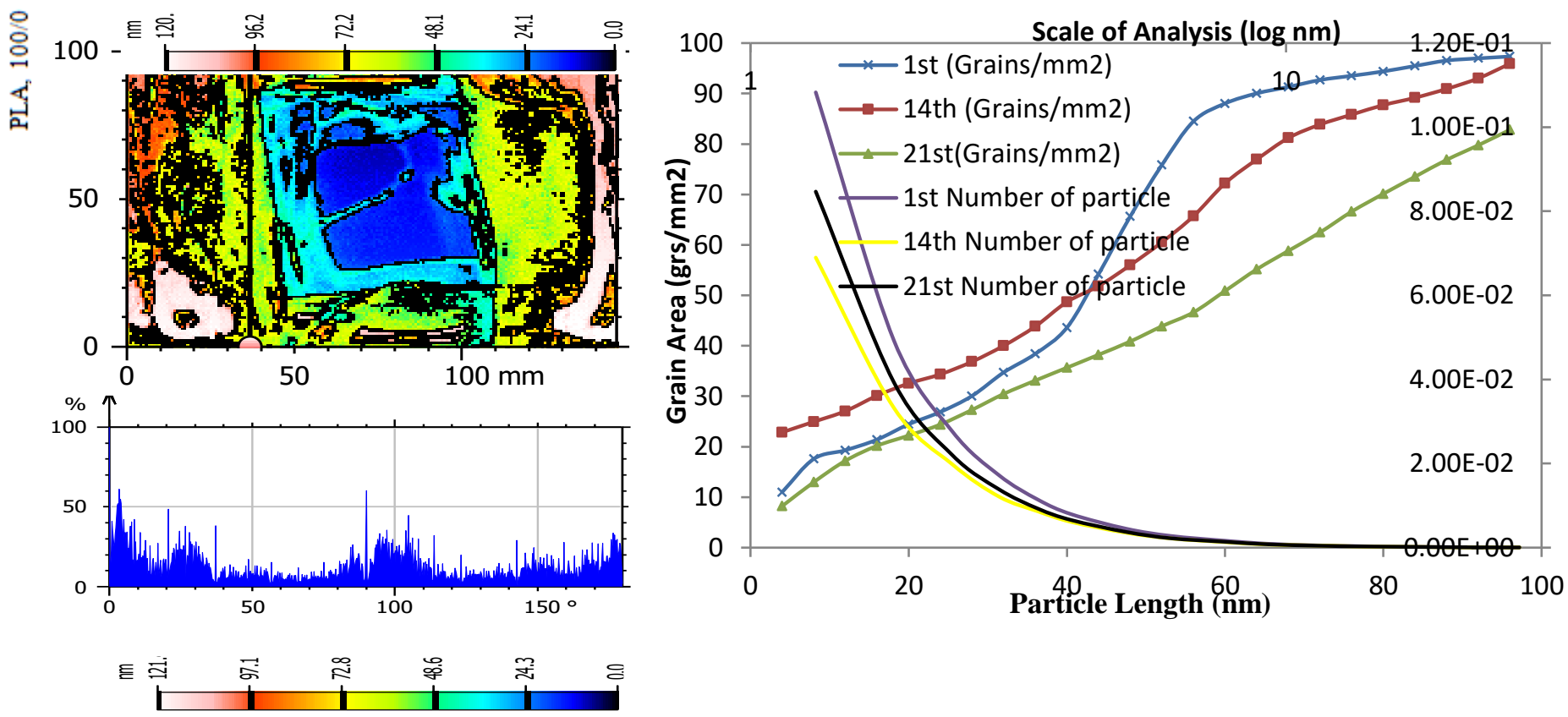

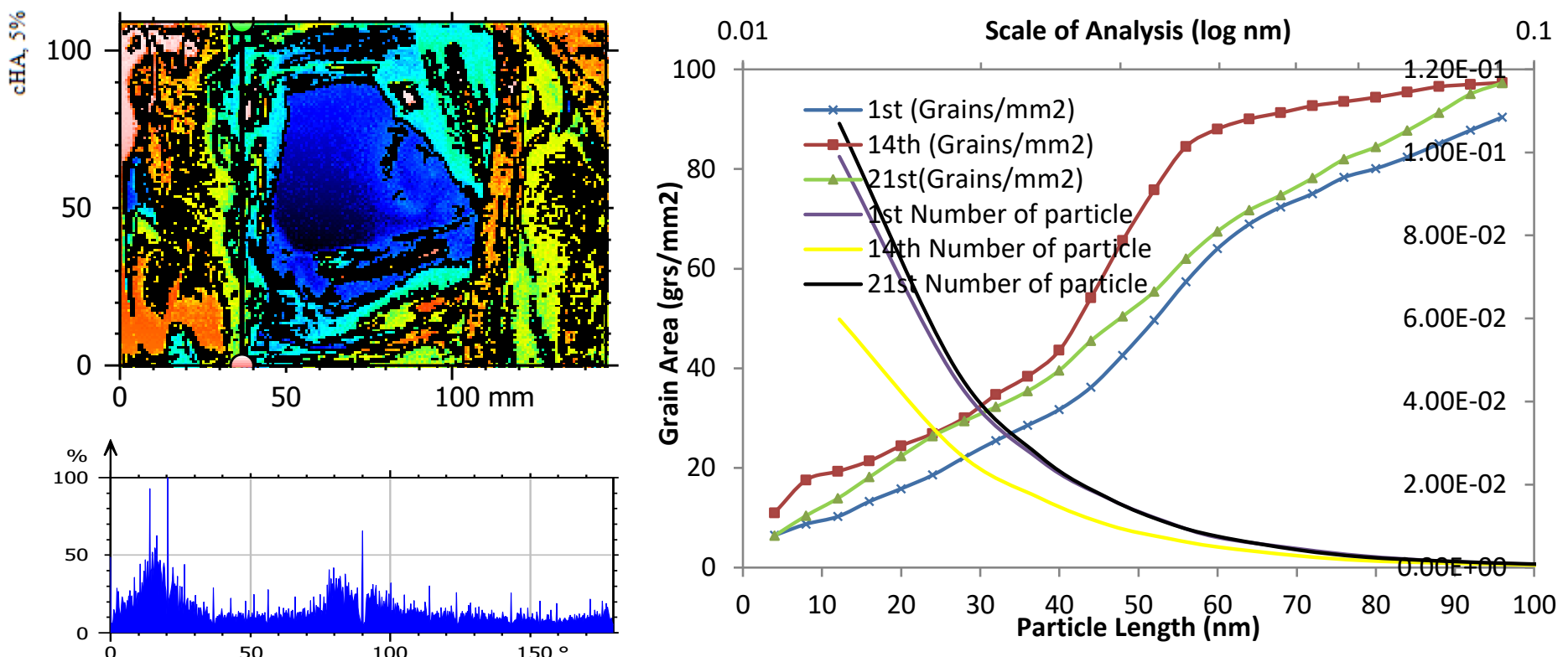

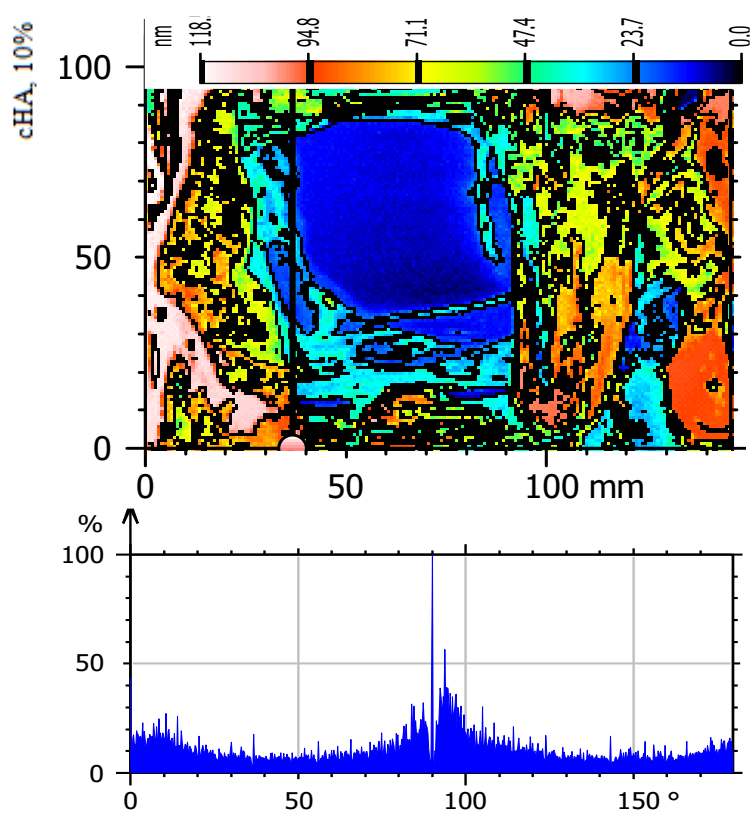

(a)

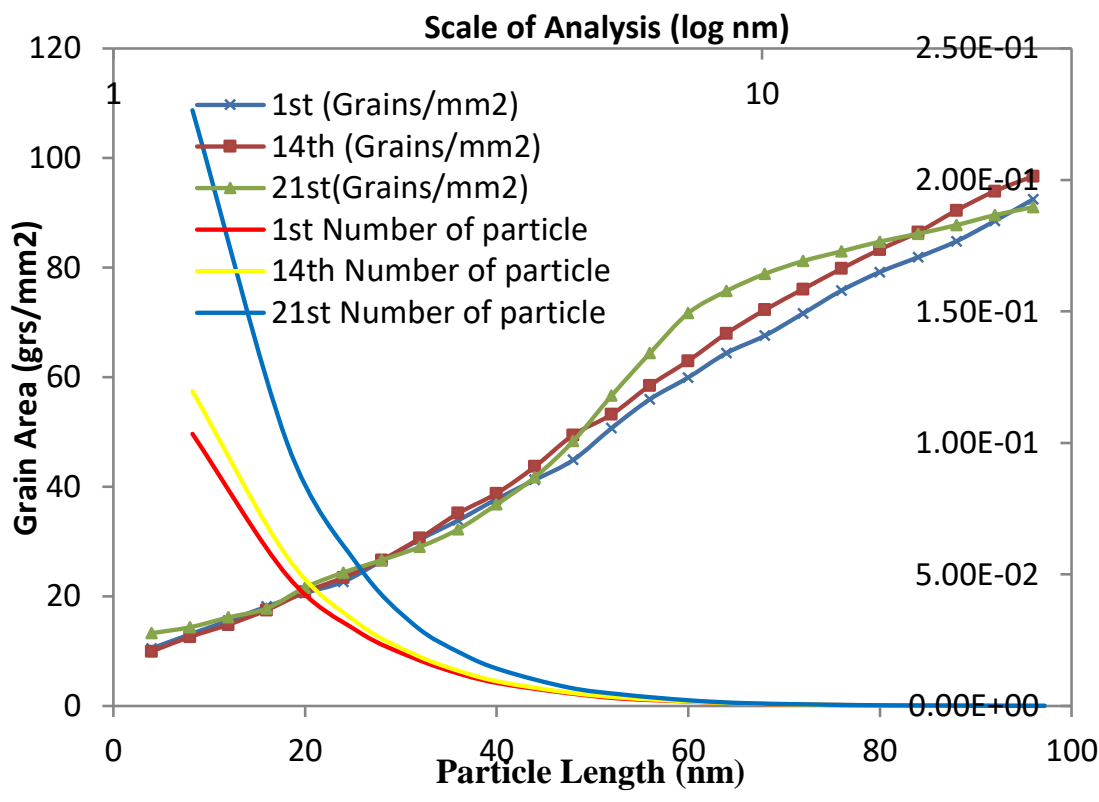

(b)

Fig. 8. The composite representations for cHA 0\%, 5\% and 10\%, showing their (a) contour line-level simulation microstructural details and texture directions of KL-transform and (b) peak count distribution of the nanoparticle fractal analysis of KL transform.

\subsection{Porosity detection}

The results obtained from the porosity analysis of the PLA/cHA scaffolds in the proportions of 100/0, 95/5 and 90/10 are presented in Table 1. From the data obtained, the PLA/cHA 100/0 framework $(74.8 \% \pm 1.2 \%)$ was more porous, when compared with the PLA/cHA 95/5 framework $(61.6 \% \pm 5.1)$ and 90/10 (61.6\% \pm 5.0$)$. These values established a reduction in the porosity of PLA/cHA scaffolds with load insertion. The trend of reduction can be evidently observed in Table 1 . 
Table 1

Parameters Table of the hybrid stratified surfaces of porosity in KL-transform of ISO 25178.

\begin{tabular}{|c|c|c|c|}
\hline \multicolumn{4}{|c|}{ Parameters Table - KL transform of ISO 25178} \\
\hline \multicolumn{4}{|c|}{ Parameters height } \\
\hline Materials properties & PLA/cHA $100 / 0$ & cHA $5 \%$ & cHA $10 \%$ \\
\hline Root-mean-square height (sq) & $28.29 \mathrm{~nm}$ & $28.97 \mathrm{~nm}$ & $30.56 \mathrm{~nm}$ \\
\hline Skewness (Ssk) & -0.01368 & -0.07607 & -0.06829 \\
\hline Kurtosis (Sku) & 2.195 & 1.868 & 1.900 \\
\hline Maximum peak height (Sp) & $48.11 \mathrm{~nm}$ & $52.49 \mathrm{~nm}$ & $49.56 \mathrm{~nm}$ \\
\hline Maximum pit height (Sv) & $51.89 \mathrm{~nm}$ & $47.51 \mathrm{~nm}$ & $50.44 \mathrm{~nm}$ \\
\hline Maximum height & $100.0 \mathrm{~nm}$ & $100.0 \mathrm{~nm}$ & $100.0 \mathrm{~nm}$ \\
\hline Arithmetic mean height & $22.76 \mathrm{~nm}$ & $25.21 \mathrm{~nm}$ & $25.88 \mathrm{~nm}$ \\
\hline \multicolumn{4}{|c|}{ Functional and spatial parameters } \\
\hline Areal material ratio (Smr) & $100.0 \%$ & $100.0 \%$ & $100.0 \%$ \\
\hline Inverse areal material ratio (Smr) & $43.25 \mathrm{~nm}$ & $37.44 \mathrm{~nm}$ & $43.01 \mathrm{~nm}$ \\
\hline Extreme peak height (Sxp) & $50.91 \mathrm{~nm}$ & $51.77 \mathrm{~nm}$ & $51.96 \mathrm{~nm}$ \\
\hline Autocorrelation length (Sal) & $34.58 \mathrm{~nm}$ & $29.60 \mathrm{~nm}$ & $28.32 \mathrm{~nm}$ \\
\hline Texture direction(Std) & $3.494^{\circ}$ & $15.75^{\circ}$ & $94.00^{\circ}$ \\
\hline \multicolumn{4}{|c|}{ Hybrid and functional parameters } \\
\hline Root-mean-square gradient (Sdq) & $2.323 \mathrm{e}-05$ & $2.389 \mathrm{e}-05$ & $2.237 \mathrm{e}-05$ \\
\hline Developed interfacial area ratio(Sdr) & $2.714 \mathrm{e}-08 \%$ & $2.851 \mathrm{e}-08 \%$ & $2.497 \mathrm{e}-08 \%$ \\
\hline Material volume (Vm) & $3.705 \mathrm{e}-07 \mathrm{~mm}^{3} / \mathrm{mm}^{2}$ & $8.765 \mathrm{e}-07 \mu \mathrm{m}^{3} / \mu \mathrm{m}^{2}$ & $4.519 \mathrm{e}-07 \mu \mathrm{m}^{3} / \mu \mathrm{m}^{2}$ \\
\hline Void volume (Vv) & $4.362 \mathrm{e}-05 \mu \mathrm{m}^{3} / \mu \mathrm{m}^{2}$ & $3.832 \mathrm{e}-05 \mu \mathrm{m}^{3} / \mu \mathrm{m}^{2}$ & $4.346 \mathrm{e}-05 \mu \mathrm{m}^{3} / \mu \mathrm{m}^{2}$ \\
\hline Peak material volume (Vmp) & $3.705 \mathrm{e}-07 \mu \mathrm{m}^{3} / \mu \mathrm{m}^{2}$ & $8.765 \mathrm{e}-07 \mu \mathrm{m}^{3} / \mu \mathrm{m}^{2}$ & $4.519 \mathrm{e}-07 \mu \mathrm{m}^{3} / \mu \mathrm{m}^{2}$ \\
\hline Core material volume (Vmc) & $2.88 \mathrm{e}-05 \mu \mathrm{m}^{3} / \mu \mathrm{m}^{2}$ & $3.132 \mathrm{e}-05 \mu \mathrm{m}^{3} / \mu \mathrm{m}^{2}$ & $3.373 \mathrm{e}-05 \mu \mathrm{m}^{3} / \mu \mathrm{m}^{2}$ \\
\hline Core void volume (Vvc) & $4.07 \mathrm{e}-05 \mu \mathrm{m}^{3} / \mu \mathrm{m}^{2}$ & $3.605 \mathrm{e}-05 \mu \mathrm{m}^{3} / \mu \mathrm{m}^{2}$ & $4.094 \mathrm{e}-05 \mu \mathrm{m}^{3} / \mu \mathrm{m}^{2}$ \\
\hline Pit void volume (Vvv) & $2.919 \mathrm{e}-06 \mu \mathrm{m}^{3} / \mu \mathrm{m}^{2}$ & $2.272 \mathrm{e}-06 \mu \mathrm{m}^{3} / \mu \mathrm{m}^{2}$ & $2.521 \mathrm{e}-06 \mu \mathrm{m}^{3} / \mu \mathrm{m}^{2}$ \\
\hline \multicolumn{4}{|c|}{ Stratified surfaces and properties parameter } \\
\hline Core roughness depth (Sk) & $2.144 \mathrm{~nm}$ & $2.722 \mathrm{~nm}$ & $1.771 \mathrm{~nm}$ \\
\hline Reduced summit height (Spk) & $1.989 \mathrm{~nm}$ & $2.056 \mathrm{~nm}$ & $1.674 \mathrm{~nm}$ \\
\hline Reduced valley depth (Svk) & $2.100 \mathrm{~nm}$ & $1.999 \mathrm{~nm}$ & $1.751 \mathrm{~nm}$ \\
\hline Upper bearing area (Smr1) & $15.39 \%$ & $14.21 \%$ & $15.45 \%$ \\
\hline Lower bearing area (Smr2) & $84.05 \%$ & $86.22 \%$ & $84.03 \%$ \\
\hline Plateau root-mean-square roughness (Spq) & 1.193 & 1.331 & 0.9887 \\
\hline Valley root-mean-square roughness (Svq) & 9.819 & 2.843 & 3.444 \\
\hline Material ratio at plateau-to-valley transition (Smq) & 99.22 & 95.63 & 97.21 \\
\hline Density of peaks (Spd) & $0.08119 \mu \mathrm{m}^{-2}$ & $0.1357 \mu \mathrm{m}^{-2}$ & $0.04197 \mu \mathrm{m}^{-2}$ \\
\hline Arithmetic mean peak curvature (Spc) & $0.0001698 \mu \mathrm{m}^{-2}$ & $0.00019 \mu \mathrm{m}^{-2}$ & $0.0001522 \mu \mathrm{m}^{-2}$ \\
\hline Ten point height $(\mathrm{S10z})$ & $100.0 \mathrm{~nm}$ & $100.0 \mathrm{~nm}$ & $97.64 \mathrm{~nm}$ \\
\hline
\end{tabular}




\begin{tabular}{llll}
\hline Five-point peak height (S5p) & $48.11 \mathrm{~nm}$ & $52.49 \mathrm{~nm}$ & $49.56 \mathrm{~nm}$ \\
Five-point pit height (S5v) & $51.89 \mathrm{~nm}$ & $47.51 \mathrm{~nm}$ & $48.08 \mathrm{~nm}$ \\
Mean dale area (Sda) & $11.73 \mu \mathrm{m}^{2}$ & $7.843 \mu \mathrm{m}^{-2}$ & $22.16 \mu \mathrm{m}^{-2}$ \\
Mean hill area (Sha) & $9.968 \mu \mathrm{m}^{2}$ & $7.076 \mu \mathrm{m}^{-2}$ & $20.60 \mu \mathrm{m}^{-2}$ \\
Mean dale volume (Sdv) & $1.176 \mathrm{e}-05 \mu \mathrm{m}^{3}$ & $6.904 \mathrm{e}-06 \mu \mathrm{m}^{3}$ & $4.981 \mathrm{e}-05 \mu \mathrm{m}^{3}$ \\
Mean hill volume (Shv) & $6.659 \mathrm{e}-06 \mu \mathrm{m}^{3}$ & $5.437 \mathrm{e}-06 \mu \mathrm{m}^{3}$ & $1.412 \mathrm{e}-05 \mu \mathrm{m}^{3}$ \\
\hline
\end{tabular}

\section{Conclusions}

Based on the experimental procedure proposed in this work, it was evident that additively manufactured PLA/cHA scaffolds can be produced, using FDM, inexpensive and simple 3D printing techniques. It involved production of filaments by melt mixing and extrusion methods. The scaffolds presented efficient insertion and good dispersion of the cHA charge in the studied two load levels of $5 \%$ and $10 \%$, with interaction in the amorphous phase of the polymeric matrix. The results obtained from the PLA/cHA scaffolds showed the effect of cHA, included a low proportion of 5\%, on the thermal and morphological properties of the scaffolds. cHA possibly acted as a nucleating agent of PLA, by reducing the crystallisation temperature and increasing the degree of crystallinity in the microstructure layer. Besides, it increased the thermal stability of the hybrid scaffolds and mechanical properties. Possibly, the presence of cHA prevented PLA degradation, due to the numerous thermomechanical processing techniques used for the production of the frameworks or scaffolds. The PLA/cHA scaffold composites in the proportions of 100/0, 95/5 and 90/10 showed adequate pore size and porosity, without compromising porosity with cHA insertion, included the scaffolds with a higher load concentration of 90/10 ratio PLA/cHA composite, as obtained from the microstructural analysis.

However, the results obtained suggested that there was a release of additives from the polymeric matrix from the various result presented in Fig. 4. In in vitro cell, computational microstructural analysis of viability tests showed non-toxic PLA/cHA frameworks predisposed to cell growth. Summarily, the present study has demonstrated the viability of production of PLA/cHA composite scaffolds in the proportions of 95/5 and 90/10. Especially, the optimum and recommended proportion of $10 \%$ of $\mathrm{cHA}$ has a promising and potential application in bone regeneration.

\section{References}

[1] Karmakar A, Acharya S, Biswas D, Arkaprabha S. Evaluation of percutaneous vertebroplasty for management of symptomatic osteoporotic compression fracture. J Clin Diagn Res 2017;11(8):7-10.

[2] Xu T, Yao Q, Miszuk JM, Sanyour HJ, Hong Z, Sun H, Fong H. Colloids Surf. B: Biointerfaces 2018; 171:31-9.

[3] Adeoye AOM, Kayode JF, Oladapo BI, Afolabi SO. Experimental analysis and optimization of synthesized magnetic nanoparticles coated with PMAMPC-MNPs for bioengineering application. St. Petersburg Polytech Univ J: Phys Math 2017;3(4):333-8.

[4] Oladapo BI, Zahedi SA, Adeoye AOM. 3D printing of bone scaffolds with hybrid biomaterials. Compos Part B: Eng 2019;158:428-36. 
[5] Oladapo BI, Zahedi SA, Vahidnia F, Ikumapayi OM, Farooq MU. Three-dimensional finite element analysis of a porcelain crowned tooth. Beni-Suef Univ J Basic Appl Sci 2018;7(4):461-4.

[6] Rakmae S, Ruksakulpiwat Y, Sutapun W, Suppakarn N. Effect of silane coupling agent treated bovine bone-based carbonated hydroxyapatite on in vitro degradation behavior and bioactivity of PLA composites. Mater Sci Eng C 2012;32(6):1428-36.

[7] Ilyas RA, Sapuan SM, Ishak MR, Isolation and characterization of nanocrystalline cellulose from sugar palm fibers (Arenga Pinnata). Carbohydr Polym 2018;181:1038-51.

[8] Ilyas RA, Sapuan SM, Ibrahim R, Abril H, Ishak MR, Zainudin ES, Asrofi M, Atikah MSN, Huzaifah MRM, Radzi AM, Azammi AMN, Shaharuzaman MA, Nurazzi NM, Syafri E, Sari NH, Norrrahim F, Jumaidin R. Sugar palm (Arenga pinnata (Wurmb.) Merr) cellulosic fiber hierarchy: a comprehensive approach from macro to the nanoscale. J Mater Res Technol 2019;8(3):2753-66.

[9] Shamsi M, Karimi M, Ghollasi M, Nezafati N, Shahrousvand M, Kamali M, Salimi A. In vitro proliferation and differentiation of on nanocomposite scaffolds based on bioactive glass $\left(64 \mathrm{SiO}_{2}-31 \mathrm{CaO}-\right.$ 5 $\left.\mathrm{P}_{2} \mathrm{O}_{5}\right)$-PLA. Mater Sci Eng C 2017;78:114-23.

[10] Yuan Q, Sahu LK, D'Souza NA, Golden TD. Synthesis of hydroxyapatite coatings on metal substrates using a spin casting technique. Mater Chem Phys 2009;116:523-6.

[11] Johnson I, Akari K, Liu H. Nanostructured hydroxyapatite/poly (lactic-co-glycolic acid) composite coating for controlling magnesium degradation in simulated body fluid. Nanotechnology 2013;24:1-16.

[12] Kothapalli CR, Shaw MT, Wei M. Biodegradable HA-PLA 3-D porous scaffolds: effect of nano-sized filler content on scaffold properties. Acta Biomater 2005;1:653-62.

[13] Moghadam MZ, Hassanajili S, Esmaeilzadeh F, Ayatollahi M, Ahmadi M. Formation of porous HPCL/LPCL/HA scaffolds with supercritical CO2 gas foaming method. J Mech Behav Biomed. Mater 2017;69:115-27.

[14] Ilyas RA, Sapuan SM, Ishak MR, Zainudin ES, Development and characterization of sugar palm nanocrystalline cellulose reinforced sugar palm starch bionanocomposites. Carbohydr Polym 2018;202:186-202.

[15] Ilyas RA, Sapuan SM, Sanyang ML, Ishak MR, Zainudin ES. Nanocrystalline cellulose as reinforcement for polymeric matrix nanocomposites and its potential applications: A review. Cur Analyt Chem 2018;14: 203-25.

[16] Krishna KV, Kanny K. The effect of treatment on kenaf fiber using a green approach and their reinforced epoxy composites. Compos B Eng 2016;104:111-7.

[17] Omigbodun FT, Oladapo BI, Bowoto OK, Adeyekun FP. Experimental model design and simulation of air conditioning system for energy management. Int Res J Eng Technol 2019;6(6):811-6.

[18] Omigbodun FT, Oladapo BI, Bowoto OK, Adeyekun FP. Modelling detection of magnetic hysteresis properties with a microcontroller. Inte J Eng Trends Technol 2019;67(6):5-12.

[19] Balogun VA, Oladapo BI. Electrical energy demand modeling of 3D printing technology for sustainable manufacture. Int J Eng 2016;29(7):954-61.

[20] Etaati A, Pather S, Fang Z, Wang H. The study of fiber/matrix bond strength in short hemp polypropylene composites from dynamic mechanical analysis. Compos B Eng 2014;62:19-28. 
[21] Taib RM, Ghaleb ZA, Ishak ZAM. Thermal, mechanical, and morphological properties of polylactic acid toughened with an impact modifier. Appl Polym Sci 2012;123(5):2715-25.

[22] Akindoyo JO, Beg MDH, Ghazali S, Heim HP, Feldmann M. Effects of surface modification on dispersion, mechanical, thermal and dynamic mechanical properties of injection-molded PLAhydroxyapatite composites. Compos A Appl Sci Manuf 2017;103:96-105.

[23] Oladapo BI, Zahedi SA, Chaluvadi SC, Bollapalli SS, Ismail M. Model design of a superconducting quantum interference device of magnetic field sensors for magnetocardiography. Biomed Sig Proc Cont 2018;46:116-20.

[24] Oladapo BI, Zahedi SA, Omigbodun FT,. Oshin EA, Adebiyi VA, Malachi OB. Microstructural evaluation of aluminum alloy A365 T6 in machining operation. J Mater Res Technol 2019;8(3),3213-22.

[25] Halimatul MJ, Sapuan SM, Jawaid M, Ishak MR, Ilyas RA. Effect of sago starch and plasticizer content on the properties of thermoplastic films: mechanical testing and cyclic soaking-drying. Polimery 2019;6:42231.

[26] Abril H, Basri A, Muhammad F, Fernando Y, Hafizulhaq F, Mahardika M, Sugiarti E, Sapuan SM, Ilyas RA, Stephane I. A simple method for improving the properties of the sago starch films prepared by using ultrasonication treatment. Food Hydrocoll 2019;93:276-83.

[27] Atikah MSN, Ilyas RA, Sapuan SM, Ishak MR, Zainudin ES, Ibrahim R, Atiqah A, Ansari MNM, Jumaidin R. Degradation and physical properties of sugar palm starch/sugar palm nanofibrillated cellulose bionanocomposite. Polimery 2019;10:680-9.

[28] Halimatul MJ, Sapuan SM, Jawaid M, Ishak MR, Ilyas RA. Water absorption and water-solubility properties of sago starch biopolymer composite films filled with sugar palm particles. Polimery 2019;9:595-603.

[29] Zahedi SA, Kodsi C, Berto F. Numerical predictions of U-notched sample failure based on a discrete energy argument. Theor Appl Frac Mech 2019;100:298-306.

[30] Zahedi SA, Demirel M, Roy A, Silberschmidt VV. FE/SPH modeling of orthogonal micro-machining of fcc single crystal. Comput Mater Sci 2013;78:104-9.

[31] Ilyas RA, Sapuan SM, Ishak MR, Zainudin ES. Sugar palm nano fibrillated cellulose (Arenga pinnata (Wurmb.)Merry): effect of cycles on their yield, physic-chemical, morphological and thermal behavior. Int J Biol Macromol 2019;123:379-88.

[32] Sanyang ML, Ilyas RA, Sapuan SM, Jumaidin R. Sugar palm starch-based composites for packaging applications. In: Jawaid M, Swain S. (eds) Bionanocomposites for Packaging Applications. Springer, Cham. 2018. p. 125-47.

[33] Ilyas RA, S.M. Sapuan, M.R. Ishak, E.S. Zainudin. Sugar palm nanocrystalline cellulose reinforced sugar palm starch composite: degradation and water-barrier properties. Mater Sci Eng 2018;368:1-12.

[34] Zahedi SA, Li S, Roy A, Babitsky V, Silberschmidt VV. Application of smooth-particle hydrodynamics in metal machining. J Phys: Conf Ser 2012;382(1):1-5.

[35] Oladapo BI, Adeoye AOM, Ismail M. Analytical optimization of a nanoparticle of microstructural fused deposition of resins for additive manuf. Compos Part B Eng 2018;150(1):248-54,

[36] Ijagbemi CO, Oladapo BI, Campbell HM, Ijagbemi CO. Design and simulation of fatigue analysis for a vehicle suspension system (VSS) and its effect on global warming. Procedia Eng 2016;159:124-32. 
[37] Correa C, Razzino C, Hage JR. Role of maleated coupling agents on the interface adhesion of polypropylene-wood composites, J Thermoplast Compos Mater 2007;20(3):323-39.

[38] Gupta B, Revagade N, Hilborn J. Poly (lactic acid) fiber: An overview. Prog Polym Sci 2007;32(4):45582.

[39] Borum-Nicholas L, Wilson O. Surface modification of hydroxyapatite Part I. dodecyl alcohol, Biomaterials 2003;24(21):3671-9.

[40] Ren Z, Dong L, Yang Y. Dynamic mechanical and thermal prperties of plasticized poly (lactic acid). J Appl Polym Sci 2006;101(3):1583-90. 